\title{
A review on quality from the perspective of industrial product design assessment
}

\author{
Alexandra Elena Crăciun \\ University Politehnica of Bucharest, Department of Manufacturing Engineering, \\ Bucharest, Romania \\ craciun_alexandra@outlook.com
}

\begin{abstract}
The design assessment of an industrial product implies the objective approach of the product from both technical and aesthetic perspective, considering the market segment and its relation to the product through ergonomic and also signification associations, all of this taking into account functionality and the perceived quality of a product. The presented paper represents a review on quality in its relation to product design by analysing in turn the relations between quality, product, design and user and establishing the common concepts associated to quality related to each design dimension. The research contributes to the understanding of quality when is addressed from the point of view of industrial design assessment.
\end{abstract}

Keywords. industrial product design, design assessment, product quality.

\section{Introduction}

The concept of product quality is extensively discussed, being deepened from different perspectives depending on the segment in question. Most often studies that are based on the fundamental works in the field of quality approach the term from the perspective of conformance to requirements as is the case with Crosby [1], or fitness for use for Juran [2]. Taken out of context, the approaches can be considered incomplete, therefore, a broader approach to the term quality also related with Juran is "those features of products which meet customer needs and thereby provide customer satisfaction", definition associated with the components of the quality trilogy: quality planning (meeting consumer needs), quality control (problem diagnostic) and quality improvement (deficiencies elimination) [2]. According to Feigenbaum, quality control is considered a system that integrates quality development, quality maintenance and quality improvement in order to obtain full customer satisfaction [3], while quality improvement represents constant development of all key aspects involved in qualitative processes and is most often associated to Taguchi through the study of robust products and parameter design [4].

Regarding the idea of quality improvement and adopting structured management principles, it arises the concept of total quality management (TQM) most often attributed to Deming [5]. The principles of quality management are also approached in the family of ISO 9000 standards, presented as: customer focus, leadership, engagement of people, process approach, improvement, evidence-based decision making and relationship management [6]. It is said that there are over one million companies that are ISO 9001 certified (this being the only standard in the 9000 family that can be certified) [7] as there are multiple benefits associated to them among which the main advantage is the increase of productivity.

Regarding the relation of quality with design, quality is a component of major importance in design and not only the quality of the manufacturing process and even the quality of the product must be ensured by the design process, as design quality is strongly related to the improvement of product quality [8]. 
Neglecting quality can affect product design and implicitly the product's characteristics [9] and considering quality as an integrated design component, it is important to be taken into account all the more so as the proper approach to design involves multiple benefits even though the design process itself is often overlooked [10].

The definition of the term design is often surrounded by ambiguity, being addressed distinctly depending on the context and being most often associated with only the appearance of the product. An important aspect when addressing design is its association with the industrial component, as Industrial Design Society of America defines industrial design as "the professional practice of designing products, devices, objects and services used by millions of people around the world every day", emphasizing aspects related to "appearance, functionality and manufacturability of a product" that extends to "value and experience a product or service provides for end-users" [11]. Therefore, when addressing industrial design assessment, all elements involved in the design process are relevant, both those related to appearance and functionality, as the component of quality may be related to technical and aesthetic aspects as well and may influence not only the objective quality of the product as well as its perceived quality.

\section{Relations between components quality - product - design - user}

Considering the concepts of product quality and product design and taking into account that they relate to the user, four components of analysis were proposed as quality, product, design and user. In order to have an overview and understand how the quality component can be integrated in the product design assessment, the six study relations were analyzed in turn as seen in Figure 1.

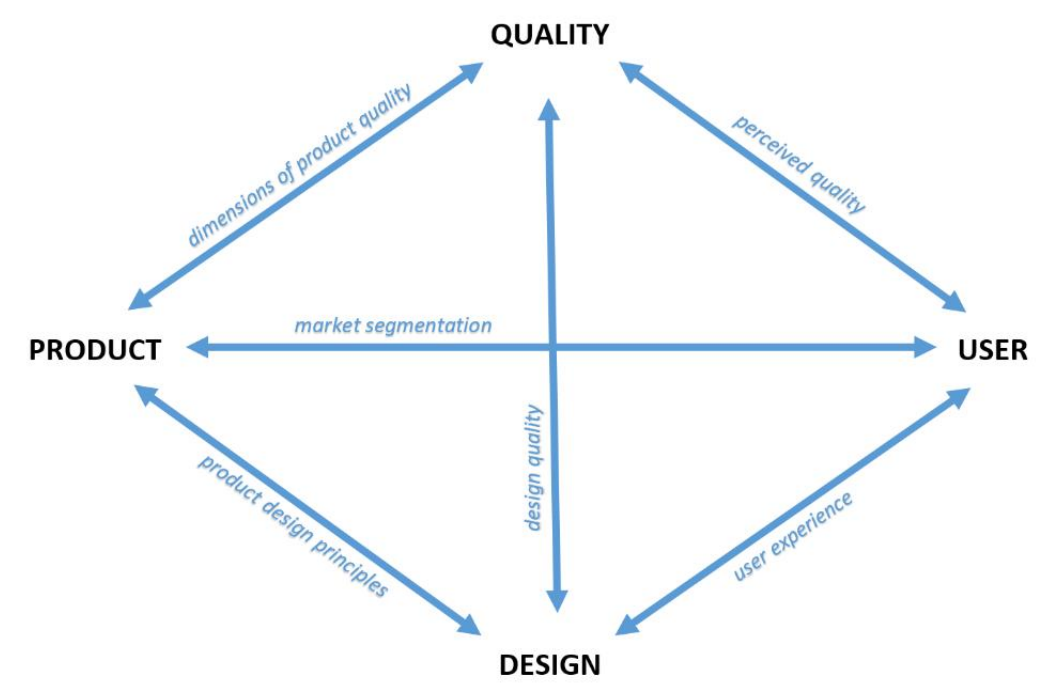

Figure 1. Relations between components.

\subsection{Product and Quality}

In the relation between product and quality a relevant and well known concept is represented by the dimensions of product quality described by Garvin as: performance (primary objective characteristics), features (secondary objective characteristics), reliability (probability of failure), conformance (reporting to pre-established standards), durability (product life, reparability), serviceability (competence of repair), aesthetics (product appearance) and perceived quality (product reputation) [12], since taking these principles into account is considered important in a strategic approach. In terms of manufacturing goods companies, the importance of the relation between quality and product is all the greater as product quality can have a strong impact on the competitive advantage [13] and can also be associated with brand identity [14]. 


\subsection{Quality and User}

There is a direct association between user and the considered quality of a product, which is highlighted even from the purchase process as buying behaviour. The purchase decision is related to the perceived quality, perceived value as the utility associated with the product and perceived risk as acquisition uncertainty [15]. When referring to perceived quality, Zeithaml associates quality to superiority and excellence, and considers the perceived quality as being only a reaction from the consumer as a distinct component from the objective quality associated to technical superiority [16]. The perception of quality is related to the customer experience with the product performance [17], and is not to be neglected the fact that the perceived quality may also be affected by the quality of the products' attributes themselves, especially the surface finish that is strongly related to perceived quality. Approached from a sensory perspective, the perceived quality of a product takes into account the relation between user and product attributes as visual (referring to visual harmony that derives from general pattern or colour associations), auditory (the auditory reaction having a great importance in relation to the perceived quality of a product), tactile (reaction related to touch and feel) and olfactory (most often related to the material) [18].

\subsection{Product and User}

The relation between product and user is approached from the perspective of consumer behaviour with implications in market segmentation. The general market segmentation categories are demographic, geographic, psychographic and behavioural segmentation [19][20], representing an analysis of the consumer's typology and its differentiating elements. Also, it is not only relevant to determine a given segment, there are factors that influence consumer behaviour such as the personal factor like age, occupation or personality traits, psychological factor like motivation, social factor linked to culture and economic factor such as income [21]. The product and the user are in a direct relation, as the product is intended and designed according to the user's typology, so all product characteristics must be related to it, not just ergonomically and functionally and by associated features, such as colour, shape, size or material.

\subsection{User and Design}

Product design goes beyond relating the user's typology with the corresponding product attributes, since the relation between user and product should be considered altogether, taking into account the interaction between the two components and the actual use experience as a process, context of use being in this case a relevant component [22]. Human experience, through its relation to context, represents a relevant factor in understanding the product's usability [23], both from the perspective of the relation between human involvement and the use process and also the relation between the product and its environment of use [24]. Understanding usability and its implications is a key factor all the more so as the context can affect the perception on attractiveness and product quality [25]. In the relation between design and user, the best know standards are ISO 9241-210:2019 [26], ISO 9241-11:2018 [27] and ISO 6385:2016 [28] that addresses mainly the ergonomic aspects.

\subsection{Product and Design}

In a study on the concept of good product design, considering the specialized literature and design competitions, Demirbilek and Park have structured the general criteria used in the design analysis as: beauty, meeting the needs of clients, benefiting the users, easy to maintain and easy to clean, good value for the price, enhances or improves life, environmental conscious, functionality, going beyond function, durability, unpretentious, creativity and originality, recognizable, simple and smart [29]. Industrial products are designed to primarily serve a purpose, as Merino et al. when assessing usability in product design, have proposed the following principles: consistency (similar tasks must be performed in similar ways), compatibility (the way the product works must relate to the user's expectation), capacity (taking into account the capacities of the user), feedback (the product interface must provide relevant feedback to the user), prevention and error correction (the product must minimize the possibilities of errors caused 
by the user), control by the user (control over the interactions), visual clarity (easy to understand information), prioritizing of functionality and information (products must be easily operated), adequate transference of technology (the product's usability must be highlighted), evidence (the product must clearly indicate its purpose and operating mode) [30].

\subsection{Design and Quality}

In a general approach to design quality, the intended essential design aspects are correlated to certain desired specifications [31], as is the case when quality of design is considered to be the minimum variation between product features and customer needs [32]. Thus, when approaching design and quality in the same context, their relation cannot be considered without integrating either the product or user component, as another approach in design quality relates it to product quality that derives from the design process and manufacturing quality [8].

\section{Quality in design assessment}

Interpreting the analysed sections, it can be observed that a main component of product quality is associated with pre-production or production phase, such as quality planning or quality control, especially when error prevention is considered. However, approaching the study from the perspective of assessment, based on the design assessment dimensions [33], the relevant concepts associated to the relation between design and quality were structured and presented in Table 1 . In order to eliminate redundancy, the recurring terms were reduced as well as the resembling concepts.

Table 1. Quality components from the perspective of design assessment.

\begin{tabular}{lc}
\hline $\begin{array}{l}\text { Design assessment } \\
\text { dimensions }\end{array}$ & $\begin{array}{c}\text { Associated concepts } \\
\text { reliability as probability of failure } \\
\text { durability } \\
\text { Functional } \\
\text { serviceability and ease of repair } \\
\text { usability and ease of use } \\
\text { consistency and compatibility as the product must relate to the user } \\
\text { expectations and aid prevention and error correction } \\
\text { originality as creativity and innovation }\end{array}$ \\
\hline Technical & performance \\
conformance to technical standards
\end{tabular}

It can be observed that, broadly, aspects concerning functionality are mainly related to the product's usability, since, assessing the product's functionality implies direct contact with the product. Also, conformance can be considered through all dimensions both from a technical perspective whether we refer to specifications or tolerances, as well as the other dimensions such as ergonomic through conformance to anthropometry, symbolistic for conformance to cultural associations and aesthetic for conformance to context of use that affects the perception on attractiveness, all this being underlined by the fact that a key aspect when it comes to quality is the extent to which the product relates to the user. 


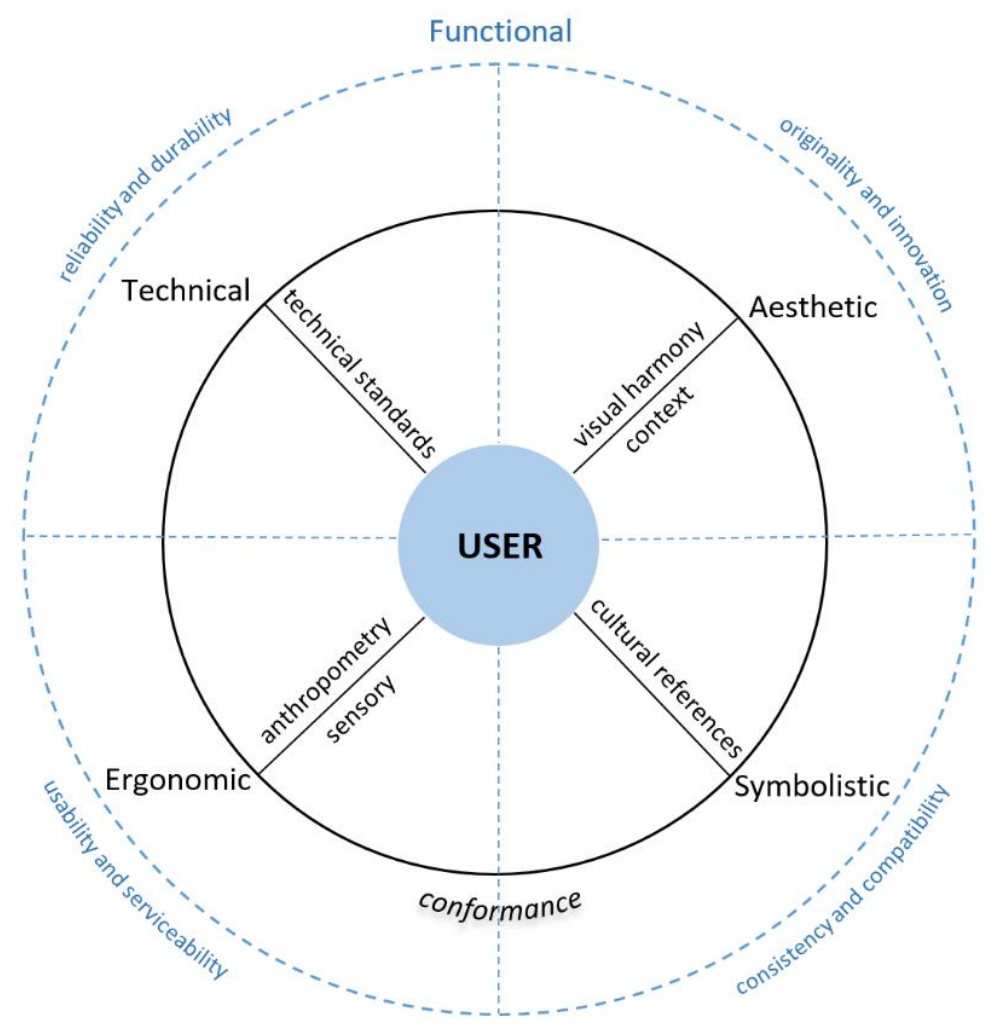

Figure 2. Design assessment dimensions approached from the quality perspective.

The proposed approach to quality is user-centered as can be seen in Figure 2 and addresses the assessment dimensions in relation to conformance to the user, taking into account its typology and associated specifications. As can be observed, the functional dimension is approached differently, since functionality in design assessment has the highest ratio of importance and it does not relate directly to the products features but emphasizes the user experience [33], whereas for the other considered dimensions, the degree of conformance of the product's features can be analyzed individually for each dimension, for example the product's shape from an ergonomic point of view is addressed differently compared to its aesthetic approach.

\section{Conclusions}

In the presented study were considered the relations between product and quality from the perspective of the dimensions of product quality, quality and user considering the buying behavior and perceived quality of a product, product and user regarding market segmentation and user typology, user and design as user experience and ergonomic considerations, product and design considering assessment principles and usability in design and design and quality from the perspective of the design quality that is implicitly correlated with both the product and the consumer.

Following the analysis, it was observed that certain essential components related to quality and quality assurance cannot be addressed in the design assessment, but their effects are implicitly reflected in the final product. However, the corresponding terms that can be considered in the assessment were interpreted and associated accordingly with the considered dimensions. Thus, the presented paper highlights the quality component from the perspective of industrial design assessment for each dimension. 
If product improvement is desired after the assessment, design can be approached in reverse, starting from establishing the parameters that require improvement and addressing quality again in the redesign process, as it can be reconsidered also the relation between the user requirements and the attributes of the product in question. Centered especially on the needs of the customer, quality function deployment represents a tool that, although its applicability is greater for development, it can also be used to improve design [34]. Sure enough, there are also a multitude of other tools and techniques that can be used with success to consider and improve design, choosing a certain technique depending on the desired approach and its applicability to the given case [35].

Regarding the research's limits, although it does not have a major impact on the current study, the term user was used in associations with client, buyer or consumer. Certainly, there is the possibility that the buyer is not the actual user of the product in question and the distinct implications can be further studied.

\section{Acknowledgement}

This work has been funded by the European Social Fund from the Sectoral Operational Programme Human Capital 2014-2020, through the Financial Agreement with the title "Scholarships for entrepreneurial education among doctoral students and postdoctoral researchers (Be Antreprenor!)", Contract no. 51680/09.07.2019 - SMIS code: 124539.

\section{References}

[1] P. CROSBY: Quality is Free, McGraw-Hill, New York, NY, 1979

[2] J. M. JURAN, A. B. GODFREY: Juran's Quality Handbook $5^{\text {th }}$ edition, McGraw-Hill, New York, 1999

[3] A. V. FEIGENBAUM: Total Quality Control $3^{\text {rd }}$ edition, McGraw-Hill, New York, 1983

[4] G. TAGUCHI, S. CHOWDHURY, Y WU: Taguchi's Quality Engineering Handbook, John Wiley \& Sons, New Jersey, 2005

[5] W. E. DEMING: Out of the crisis, Massachusetts Institute of Technology, Cambridge, 1986

[6] Quality management principles. Retrieved from https://www.iso.org/files/live/sites/isoorg/files/store/en/PUB100080.pdf

[7] About ISO 9000 family. Retrieved from https://www.iso.org/iso-9001-quality-management.html

[8] Z. YANMEI, R. ALARD, P. SCHOENSLEBEN: Design Quality: A Key Factor to Improve in International Production Networks, Advances in Production Management Systems, 246, 2007, 133-141

[9] D. CIKOTIENĖ, A. BARGELIS: Research of quality impact to the product design properties and characteristics, Mechanika, 79(5), 2009, 63-67

[10] P. KOTLER, G. A. RATH: Design: A Powerful but Neglected Strategic Tool, Journal of Business Strategy, 5(2), 1984, 16-21

[11] Industrial Design Society of America, Industrial design definition. Retrieved from https://www.idsa.org/what-industrial-design

[12] A. D. GARVIN: What Does 'Product Quality' Really Mean, MIT Sloan Management Review, 26(1), 1984

[13] A. S. DUNK: Assessing the Effects of Product Quality and Environmental Management Accounting on the Competitive Advantage of Firms, Australasian Accounting Business and Finance Journal, 1(1), 2007

[14] J. HANAYSHA, N. H. ABDUL-GHANI: The impact of product quality on relationship quality: empirical evidence from automotive industry, International Journal of Organizational and Business Excellence, 1, 2016

[15] C. H. YEE, N. C. SAN, C. H. KHOON: Consumers' Perceived Quality, Perceived Value and Perceived Risk Towards Purchase Decision on Automobile, American Journal of Economics and Business Administration, 3(1), 2011, 45-57

[16] V. A. ZEITHAML: Consumer Perceptions of Price, Quality and Value: A Means-End Model and 
Synthesis of Evidence, Journal of Marketing, 52(3), 1988, 2-22

[17] G. N. KENYON, K. SEN: A model for assessing consumer perceptions of quality, International Journal of Quality and Service Sciences, 4(2), 2012, 175-188

[18] K. STYLIDIS, C. WICKMAN, R. SÖDERBERG: Perceived Quality of Products: a Framework and Attributes Ranking Method, Journal of Engineering Design, 31(1), 2020, 37-67

[19] G. MARTIN: The Importance of Marketing Segmentation, American Journal of Business Education, 4(6), 2011, 15-18

[20] S. DOLNICAR, B. GRÜN, F. LEISCH: Market Segmentation Analysis, Springer Open, Singapore, 2018

[21] S QAZZAFI: Factor Affecting Consumer Buying Behavior: A Conceptual Study, International Journal for Scientific Research \& Development, 8(2), 2020, 1205-1208

[22] K. BONGARD-BLANCHY, C. BOUCHARD: Dimensions of User Experience - from the Product Design Perspective, Jurnal d'Interaction Personne-Système, 3(1), 2014

[23] M. CHAMORRO-KOC, V. POPOVIC, M. EMMISON: Context-of-Use and the Design of UserProduct Interactions: Exploring Causal Relationships, Design Research Society Conference, Sheffield Hallam University, 2008

[24] A. DUMITRESCU, M. E. ULMEANU, A. E. CRĂCIUN: Testing the technotope concept, UPB Scientific Bulletin, Series D, 82(3), 2020, 241-250

[25] B. SCHNURR, A. BRUNNER-SPERDIN, N. E. STOKBURGER-SAUER: The effect of context attractiveness on product attractiveness and product quality: the moderating role of product familiarity, Marketing Letters, 28(2), 2017, 241-253

[26] ISO 9241-210:2019(en) Ergonomics of human-system interaction - Part 210: Human-centred design for interactive systems. Retrieved from https://www.iso.org/obp/ui/\#iso:std:iso:9241:210:ed-2:v1:en

[27] ISO 9241-11:2018(en) Ergonomics of human-system interaction - Part 11: Usability: Definitions and concepts. Retrieved from https://www.iso.org/obp/ui/\#iso:std:iso:9241:-11:ed-2:v1:en

[28] ISO 6385:2016(en) Ergonomics principles in the design of work systems. Retrieved from https://www.iso.org/obp/ui/\#iso:std:iso:6385:ed-3:v1:en

[29] O. DEMIRBILEK, M. PARK: A survey of criteria for the assessment of good product design, Proceedings of the Fourth European Academy of Design Conference, 2001, 370-377

[30] G. SCHMIDT ALVES DÍAZ MERINO, C. S. TEIXEIRA, R. P. SCHOENARDIE, E. A DIÁZ MERINO, L. AMARAL GONTIJO: Usability in Product Design - The importance and need for systematic assessment models in product development - Usa-Design Model (U-D), IOS Press, 41, 2012, 1045-1052

[31] X. NIU, S. QUIT, H. ZHANG, M. WANG, R. WONG: Exploring product design quality control and assurance under both traditional and crowdsourcing-based design environments, Advances in Mechanical Engineering, 10(12), 2018, 1-23

[32] G. MEIROVICH: Quality of design and quality of conformance: contingency and synergistic approaches, Total Quality Management and Business Excellence, 17(2), 2006, 205-219

[33] A E. CRĂCIUN: Strategic outlook in industrial design assessment based on product category, IOP Conference Series: Materials Science and Engineering, 682, 2019, doi:10.1088/1757899X/682/1/012006

[34] N. OZLEM ERDIL, O. M. ARANI: Quality function deployment: more than a design tool, International Journal of Quality and Service Sciences, 11(1), 2018, 142-166

[35] E. LUTTERS, F. J. A. M. VAN HOUTEN, A. BERNARD, E. MERMOZ, C. S. L. SCHUTTE: Tools and techniques for product design, CIRP Annals, 63, 2014, 607-630 